Check for updates

Cite this: RSC Adv., 2018, 8, 8285

\title{
A thermo-reversible silicone elastomer with remotely controlled self-healing $\dagger$
}

\begin{abstract}
E. Ogliani, L. Yu, I. Javakhishvili and A. L. Skov (D)*
Soft thermoplastic elastomers with increased durability and reliability are in high demand for a broad spectrum of applications. Silicone elastomers are soft and durable, but they are not thermoplastic in nature, and under extreme conditions such as high voltage or large deformations, reliability may also suffer. Thus, as a solution to these shortcomings, which are typical of silicone elastomers, it is natural to propose a thermo-reversible, self-healing, and recyclable silicone-based elastomer. Stimuli-responsivity is imparted to the silicone polymer by incorporating supramolecular 2-ureido-4[1H]-pyrimidone (UPy) self-assembling motifs via free radical polymerisation. Self-healing of the novel elastomer may be triggered by both direct and indirect heating, the latter by means of incorporating $\mathrm{Fe}_{3} \mathrm{O}_{4}$ particles into the elastomer and subsequent exposure to an alternating magnetic field. As a consequence of temperature responsiveness and high thermal stability, the elastomer is proven recyclable, by withstanding multiple reprocessing procedures with no substantial effects on the resulting properties. The synergy of these valuable characteristics makes this novel material a smart candidate for innumerable applications where soft and reliable elastomers are sought.
\end{abstract}

Received 27th December 2017 Accepted 18th February 2018

DOI: $10.1039 / c 7 r a 13686 b$

rsc.li/rsc-advances high selectivity and directionality. In the design of reversible self-assembling polymer systems, 2-ureido-4[1H]-pyrimidone $(\mathrm{UPy})^{13}$ is one of the most exploited associating groups, owing to its unique features of a self-complementary DDAA (donordonor-acceptor-acceptor) array of four hydrogen bonds. ${ }^{\mathbf{1 4 , 1 5}}$ In previous work, we reported the synthesis of 2-methoxyethyl acrylate (MEA) and 6-methyl-2-ureido-4[1H]-pyrimidonebearing methacrylate (UPyMA) random copolymers, ${ }^{16}$ with the aim of clarifying the dynamics of hydrogen bonds in unentangled associating polymers. Understanding the process of breaking and reforming these associations allows the manipulation of associative polymer properties, in order to tailor them to diverse applications.

Polydimethylsiloxane (PDMS) elastomers are utilised in an impressively wide range of applications, such as artificial muscles in the shape of dielectric elastomers where softness is sought, ${ }^{17}$ medical implants, ${ }^{18}$ soft robotics, ${ }^{19}$ microfluidic devices $^{20}$ and many commodities (bakeware, cosmetics, and electronics amongst others). Despite their remarkable versatility and valuable properties, however, silicone elastomers are thermoset polymers due to their covalent nature, thus they are not easily recyclable. Therefore, it is a demanding challenge to overcome this drawback without sacrificing their more favourable properties. A few examples of thermoplastic elastomers (TPEs) have been reported. One method is the development of silicone-modified thermoplastic copolymers, such as polyurethane/silicone elastomers, ${ }^{21}$ or the introduction of physical cross-links through incorporating self-associating groups in the silicone backbone. ${ }^{22}$ The introduction of
Danish Polymer Centre, Department of Chemical and Biochemical Engineering, Technical University of Denmark, Søltofts Plads, Building 229, 2800 Kgs Lyngby, Denmark.E-mail: al@kt.dtu.dk

$\dagger$ Electronic supplementary information (ESI) available. See DOI: 10.1039/c7ra13686b 
hydrogen bonds is a useful technique to provide silicone elastomers with not only thermoplastic properties, but also self-healing functionalities. Examples of supramolecular PDMS elastomers based on hydrogen bonding include the work of Yang et al. ${ }^{23}$ who reported the synthesis of a siliconebased TPE through the reaction of carboxyl-terminated PDMS with diethylenetriamine (DETA) and urea, and Tazawa et al., ${ }^{24}$ who designed thermoplastic PDMS with L-phenylalaninebased hydrogen bond networks. Nevertheless, the selfhealing processes in the previous approaches require a long time or lead to a drastic decrease in mechanical properties.

Beyond the thermoplasticity of the material, self-healing properties have been sought by alternative approaches. Corten et $a .^{25}$ introduced induction heating as a novel approach to generate heat and externally trigger polymer healing. This method consists of incorporating magnetic particles into the polymer matrix and the subsequent exposure of the composite to an alternating magnetic field (AMF). Consequently, the magnetic particles dissipate energy to the surrounding matrix, due to friction between the oscillating magnetic particles and the stationary matrix. The heat developed by the process allows for thermo-responsiveness and network rearrangement. AMF generates heat rapidly and locally, compared to supplying heat directly to the thermally insulating elastomer. Furthermore, self-healing is easily tunable by manipulating diverse parameters, such as frequency of the applied magnetic field, the nature of the susceptor material, and particle loading. Above all, the process is contactless. For instance, contactless activation becomes of interest when the material is employed as part of a component which is difficult to access, e.g. intermediate components, coatings and seals in the automotive industry. ${ }^{26}$

In this paper, we report the magnetic field-triggered selfhealing of a novel thermoplastic silicone elastomer, namely $\mathrm{P}$ (PDMSMA-co-UPyMA), resulting from the free radical polymerisation of monomethacryloxypropyl terminated polydimethylsiloxane (PDMSMA) and UPyMA monomers. This novel copolymer possesses thermoplastic properties because of the reversible nature of UPy self-associating dimers. Selfhealing of the material is activated via direct supply of heat as well as remotely by induction heating. Remotely controlled healing has been proven through exposure of the composite with $20 \mathrm{wt} \% \mathrm{Fe}_{3} \mathrm{O}_{4}$ particle filler to an AMF. Moreover, the elastomer can be remoulded multiple times, without showing noteworthy chemical or physical degradation. Hence, this novel material may be considered an excellent candidate for recyclable silicone elastomers. In addition, the described self-healing approach, using the same conditions, has been applied to the previously reported material P(MEAco-UPyMA). ${ }^{16}$ The P(PDMSMA-co-UPyMA) and P(MEA-coUPyMA) copolymers bear identical self-complementary hydrogen-bonding motifs, albeit differing in the main repeating unit. Comparing their self-healing performance under identical conditions aims at proving how the optimised self-healing procedure is versatile and not systemdependent.

\section{Experimental}

\section{Materials}

$N, N$-Dimethylformamide (DMF; Sigma-Aldrich, $\geq 99.9 \%$ ) was dried over molecular sieves. $\alpha, \alpha^{\prime}$-Azoisobutyronitrile (AIBN; Ventron) was re-crystallised from methanol. Monomethacryloxypropyl terminated polydimethylsiloxane (PDMSMA MCR-M07; Gelest, $703.3 \mathrm{~g} \mathrm{~mol}^{-1}$ as determined by ${ }^{1} \mathrm{H}$ NMR), 2-isocyanatoethyl methacrylate (Sigma-Aldrich, 98\%), 2amino-4-hydroxy-6-methylpyrimidine (Sigma-Aldrich, 98\%), iron (II, III) oxide powder $\left(\mathrm{Fe}_{3} \mathrm{O}_{4}\right.$; Sigma-Aldrich, size $<5 \mu \mathrm{m}$, 95\%), tetrahydrofuran (THF; Sigma-Aldrich, 99.9\%), methanol (Sigma-Aldrich, 99.9\%), dimethyl sulfoxide (DMSO; SAFC, $\geq 99 \%$ ), 1,4-dioxane (Sigma-Aldrich, 99.8\%), and THF- $d_{8}$ (Sigma-Aldrich, 99.8 atom\% D) were used as received. 6-Methyl2-ureido- $4[1 H]$-pyrimidone-bearing methacrylate (UPyMA) was synthesised as reported in the literature. ${ }^{15}$

\section{Analytical techniques}

Nuclear magnetic resonance (NMR) experiments were carried out on a Bruker Avance $300 \mathrm{MHz}$ spectrometer. Attenuated total reflectance Fourier transform infrared (ATR FTIR) spectra in the range of $4000-350 \mathrm{~cm}^{-1}$ were recorded on a Nicolet iS50 ATR spectrometer with a diamond crystal from Thermo Scientific. To run size exclusion chromatography, a Viscotek 200 instrument was used, provided with two PLgel mixed-D columns (Polymer Laboratories (PL)) assembled in series, and a refractive index detector, utilising THF $\left(1 \mathrm{~mL} \mathrm{~min}^{-1}\right)$ as the mobile phase operating at room temperature. Molecular weights were calculated using polystyrene (PS) standards from PL employing TriSEC software. Scanning electron microscopy (SEM) and microanalysis were performed with an FEI Quanta 200E-SEM environmental scanning electron microscope, equipped with a field emission gun. The surface was visualised in a low vacuum, using water vapour as auxiliary gas at a pressure of 150 Pa. A mixture of secondary and back-scattered electrons, generated by the sample surface, was detected with the large field detector for an incident electron beam of spot 3 accelerated to $10 \mathrm{keV}$. The elemental composition of the samples was determined by energy dispersive X-rays (EDX) with an Oxford Instruments $80 \mathrm{~mm}^{2} \mathrm{X}$-Max silicon drift detector $\mathrm{Mn} \mathrm{K} \alpha$ resolution at $124 \mathrm{eV}$, also in a low vacuum (150 Pa) with a $500 \mu \mathrm{m}$ pressure-limiting aperture X-ray cone. Microanalysis data acquisition and quantification were performed with the Oxford Instruments Aztec program version 3.1.

\section{Synthesis of P(PDMSMA-co-UPyMA)}

A Schlenk tube was charged with PDMSMA (0.97 mL, $0.43 \mathrm{mmol})$, AIBN (23 mg, $0.14 \mathrm{mmol}), \mathrm{DMF}(3.6 \mathrm{~mL})$ and 1,4-dioxane $(3.6 \mathrm{~mL})$ along with comonomer UPyMA (302 $\mathrm{mg}, 1.08 \mathrm{mmol})$. The reaction mixture was stirred and deoxygenated by bubbling nitrogen through it for $45 \mathrm{~min}$. The tube was then immersed in an oil bath at $90{ }^{\circ} \mathrm{C}$, and polymerisation was carried out for $24 \mathrm{~h}$. Thereafter, the tube was taken out of the bath and the reaction mixture exposed to the air. It was then precipitated twice from THF in a methanol-deionised water $(3: 1)$ mixture. The product was 
dried in the vacuum oven until no residual solvent was detected by spectroscopic means (yield $>60 \%$ ).

\section{Preparation of the magnetic composite}

$\mathrm{P}$ (PDMSMA-co-UPyMA) and P(MEA-co-UPyMA) magnetic composites were prepared by solvent casting a concentrated solution of the copolymers in THF and DMF, respectively. Subsequently, $20 \mathrm{wt} \% \mathrm{Fe}_{3} \mathrm{O}_{4}$ particles (size less than $5 \mu \mathrm{m}$ ) were added to the concentrated solution $\left(700 \mathrm{mg} \mathrm{mL}^{-1}\right)$, which was placed in an ultrasonic bath for 30 minutes in order to ensure the homogeneous dispersion of particles inside the matrix. The solution was cast in a metal frame $\left(4 \times 4 \times 0.1 \mathrm{~cm}^{3}\right)$ and the sample was left at room temperature or in an oven at $40{ }^{\circ} \mathrm{C}$, to allow for the slow evaporation of the solvent. The dried films were then removed from the frame and used for the experiments.

\section{Thermal properties}

Thermal transitions were measured in the range $-150{ }^{\circ} \mathrm{C}$ to $180^{\circ} \mathrm{C}$ at a heating rate of $20^{\circ} \mathrm{C} \mathrm{min}{ }^{-1}$, on a differential scanning calorimeter (DSC) Discovery series from TA Instruments. Thermogravimetric analysis (TGA) was performed from room temperature to $700{ }^{\circ} \mathrm{C}$ at a heating rate of $10{ }^{\circ} \mathrm{C} \mathrm{min}^{-1}$ and an inert atmosphere on a thermogravimetric analyser Discovery series (TA Instruments).

\section{Linear viscoelastic measurements}

Linear viscoelastic (LVE) properties of the polymer and its composites were measured with an ARES-G2 rheometer (TA Instruments), setting the instrument to a controlled strain mode, with $1 \%$ strain and frequency sweeps from $100 \mathrm{~Hz}$ to $0.01 \mathrm{~Hz}$ at 25,50 and $70{ }^{\circ} \mathrm{C}$ using parallel-plate geometry $25 \mathrm{~mm}$ in diameter.

\section{Tensile properties}

The tensile stress and tensile strain of the samples, with and without $\mathrm{Fe}_{3} \mathrm{O}_{4}$ particles and after self-healing, were measured with an ARES-G2 rheometer (TA Instruments) on a series of rectangular specimens $(18 \mathrm{~mm}$ length, $10 \mathrm{~mm}$ width and $\sim 0.7 \mathrm{~mm}$ thickness) by uniaxial extensional rheology, using an ARES-G2 rheometer with an SER2 geometry. The test specimen was elongated uniaxially at a steady Hencky strain rate of 0.01 $\mathrm{s}^{-1}$ until sample failure. All measurements were repeated three times and results are reported as the mean value of tensile stress and tensile strain at breaking, with respective standard deviation.

\section{Alternating magnetic field-triggered self-healing}

Self-healing experiments were performed using a MagneTherm instrument from Nanotherics, operating at a wide range of frequencies and consisting of a power supply, a function generator, an oscilloscope and a coil enclosure connected to a cooling system. Prior to the AMF tests, the frequency was set at $110.1 \mathrm{kHz}$ (corresponding to a magnetic field strength of 250 Oe), the composite sample was placed in the centre of a 17-loop induction coil and the experiments were then performed. A non-contact IR gun thermometer was used to detect temperature changes in the sample during AMF measurements. AMF experiments were performed in cycles of 20 minutes to avoid overheating the induction coil.

\section{Synthesis of P(MEA-co-UPyMA)}

P(MEA-co-UPyMA) was synthesised through a free radical polymerisation protocol as reported in the literature. ${ }^{16}$

\section{Results and discussion}

\section{Characterisation of P(PDMSMA-co-UPyMA)}

The thermoplastic silicone-based copolymer was synthesised via free radical polymerisation of the PDMSMA and UPyMA monomers, resulting in a random distribution of the hydrogen bonding groups along the backbone. Fig. 1a depicts the structure of the copolymer, comprising pendant, thermo-reversible UPy dimers (Fig. 1b). Successful synthesis of the copolymer was confirmed using ${ }^{1} \mathrm{H}$ NMR (Fig. S1 $\dagger$ ) and Fourier-transform infrared spectroscopy (FTIR, Fig. 1c). FTIR spectroscopy revealed characteristic absorption bands at 1662 and $1588 \mathrm{~cm}^{-1}$ belonging to the urea and pyrimidinone groups, respectively. The UPyMA molar fraction in the copolymer was quantified to $11 \%$ on the basis of ${ }^{1} \mathrm{H}$ NMR analysis (Fig. S1†). The weightaverage and number-average molecular weights, polydispersity index (PDI), and thermal properties are reported in ESI (Fig. S2 and $\mathrm{S} 3 \dagger)$.

\section{Characterisation of the copolymer and the magnetic composite}

Small-amplitude oscillatory shear rheology was performed to investigate the dynamic nature of the copolymer network and the influence of the magnetic filler on the linear viscoelastic properties of the material. Fig. 2 illustrates storage $\left(G^{\prime}\right)$ and loss $\left(G^{\prime \prime}\right)$ moduli as a function of frequency at different copolymer temperatures, with and without $\mathrm{Fe}_{3} \mathrm{O}_{4}$ particles. The rheological

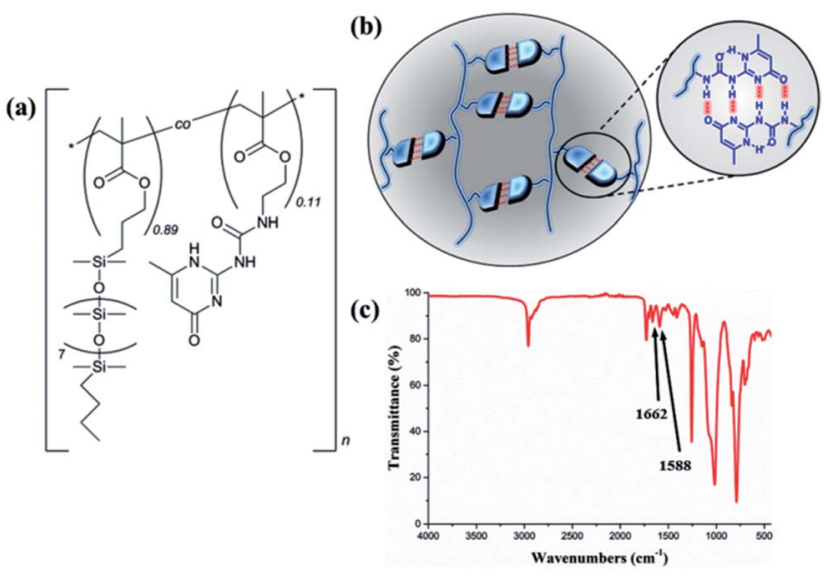

Fig. 1 (a) Chemical structure of P(PDMSMA-co-UPyMA), (b) schematic representation of multiple hydrogen-bonding interactions, and (c) FTIR spectrum of P(PDMS-Co-UPyMA). 


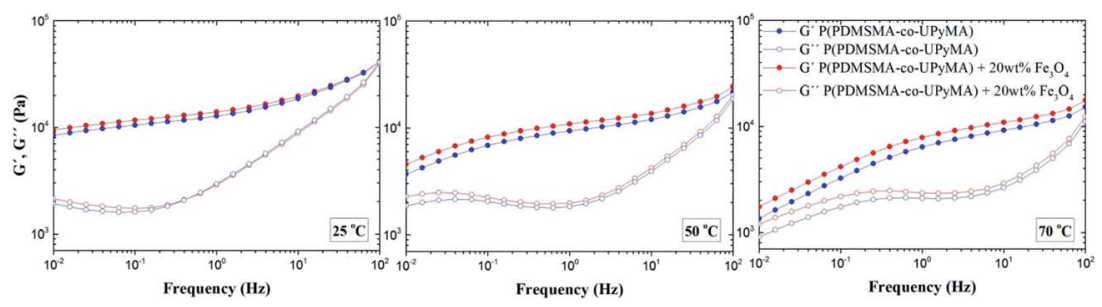

Fig. 2 Small-amplitude oscillatory shear rheology: shear storage moduli $G^{\prime}$ and shear loss moduli $G^{\prime \prime}$ of pure P(PDMSMA-cO-UPyMA) and the magnetic composite measured at $25^{\circ} \mathrm{C}, 50^{\circ} \mathrm{C}$ and $70^{\circ} \mathrm{C}$.

spectra of pure P(PDMSMA-co-UPyMA) and magnetic composite are very similar and show viscoelastic behaviour with a dominant elastic plateau at fast deformation. When the test temperature was increased, the width of the elastic plateau decreased and the terminal flow behaviour became evident at low frequencies. In particular, the onset of the terminal flow is temperature-dependent and occurs at higher frequencies for increasing temperatures, as expected from time-temperature superposition principles. These results prove the dynamic nature and the thermo-reversibility of the bonds within the supramolecular network of the copolymer, ${ }^{27}$ which are fundamental to the self-healing properties. Moreover, it was observed that the presence of the filler did not affect significantly the viscoelastic properties of the copolymer, inducing an increase in the shear storage moduli at $0.01 \mathrm{~Hz}$ of $12 \%$ and $29 \%$, at $25^{\circ} \mathrm{C}$ and $70{ }^{\circ} \mathrm{C}$, respectively.

To prepare the magnetic composite, the amount of magnetic filler was optimised in order to obtain the highest heat generation when exposed to an alternating magnetic field, without affecting the elastomeric nature of the material. The magnetic composite was then characterised by means of thermogravimetric analysis (TGA) and scanning electron microscopy (SEM). In particular, the actual value of the filler content in the composite material was assessed by TGA, which confirmed the expected value by the residual weight\% detected at the end of the experiment (Fig. S4†). From SEM analysis, it was confirmed that the elastomer composites were homogeneous (Fig. S5 $\dagger$ ). A uniform distribution of the magnetic particles within the composite is a prerequisite for the even heating of the matrix, thereby avoiding the presence of cold and hot regions. ${ }^{28}$

\section{Evaluation of self-healing efficiency}

The self-healing capability of the novel P(PDMSMA-co-UPyMA) was evaluated not only by directly heating the pure material in an oven, but also by indirectly heating the magnetic composite through exposure to an AMF. In both cases, the increase in temperature was used as a driving force to trigger the thermoreversibility of the supramolecular self-associating UPy dimers. As stated by reptation theory, ${ }^{29}$ when a material is damaged, the healing process occurs at the cut interface through surface contact and rearrangement, wetting, diffusion, and randomisation. Hence, the main aim was to prove that this silicone-based elastomer could recover after damage as a result of the thermally activated rearrangements of the hydrogen bonds at the cut interface.
First, the self-healing ability of the pure copolymer was investigated by means of direct heating. Experiments were performed by cutting the specimen with a razor blade into two equal parts, which were then rejoined by contacting the cut surfaces. Subsequently, the damaged sample was placed in an oven. Self-healing properties were investigated after 1 hour at two different temperatures, namely 55 and $70{ }^{\circ} \mathrm{C}$. At room temperature no self-healing was recorded after 1 hour. Tensile stress and tensile strain of the samples were measured before and after treatment in the oven, in order to evaluate the selfhealing efficiency of the material (Fig. S6a and Table S2 $\dagger$ ). In particular, the self-healing efficiency was determined with respect to the percentage of restored tensile strain $\left(\eta_{\varepsilon}\right)$ and tensile stress $\left(\eta_{\sigma}\right) .^{30}$ Fig. 3 shows clearly how the mechanical properties of the material healed by direct heating at $70{ }^{\circ} \mathrm{C}$ after damage were fully restored, by comparison to the mechanical properties of the native copolymer. On the other hand, direct heating at a temperature of $55{ }^{\circ} \mathrm{C}$ only led to self-healing efficiencies corresponding to $\eta_{\varepsilon}=56 \%$ and $\eta_{\sigma}=66 \%$. This behavior could be attributed to the limited amount of thermoreversible UPy dimers present in the backbone (the UPy molar fraction in P(PDMSMA-co-UPyMA) was quantified to be $11 \%$ ), so that an higher temperature is required to promote interdiffusion of the chains through the interface and rearrangements of the hydrogen bonds. Nevertheless, the reported results indicate that the pure elastomer is capable of healing completely by means of small amounts of heat.

Beyond self-healing capability, the recyclability of $\mathrm{P}$ (PDMSMA-co-UPyMA) was verified by means of solvent casting in tetrahydrofuran (THF). The tensile stress and tensile strain of the copolymer were measured after repeated reprocessing, and

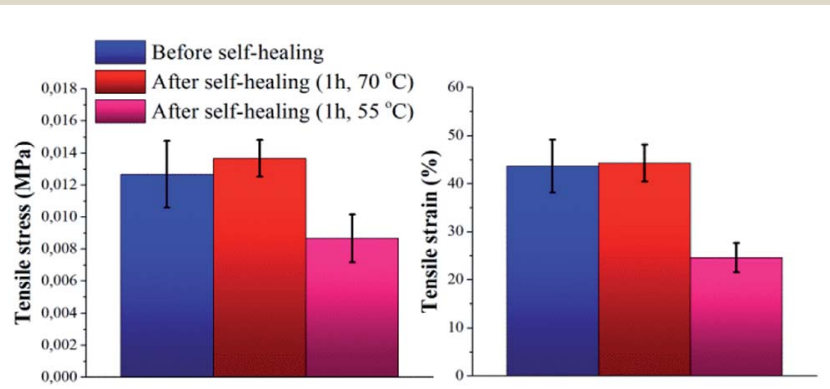

Fig. 3 Tensile stress and tensile strain of pure P(PDMSMA-CO-UPyMA), before and after healing for $1 \mathrm{~h}$ in oven at a pre-set temperature of $55^{\circ} \mathrm{C}$ and $70{ }^{\circ} \mathrm{C}$, respectively. 
no significant changes in the values were observed (Fig. 4). Hence, the material can be reshaped and reused multiple times, without losing its original properties.

Moreover, in this study, incorporating magnetic particles as a susceptor material inside the polymer matrix was employed to determine if the synthesised material is able to heal following exposure to an alternating magnetic field. Since the thermal response of the magnetic composite through exposure to an AMF depends on particle loading and the frequency of the magnetic field, ${ }^{31}$ these parameters were optimised to achieve the highest increase in temperature. Hence, a range of 10 frequencies was screened, in order to have a complete frequency-response profile of the magnetic particles embedded in the matrix. The best heating results were obtained at a frequency of $110.1 \mathrm{kHz}$, corresponding to a field strength of 250 Oe. Similarly, particle loading was optimised by evaluating the heating performance of the magnetic composite following exposure to AMF. As shown in Fig. 5, the composite with $20 \mathrm{wt} \%$ particle filler was found to have the highest final heating temperature of the bulk material, corresponding to $55{ }^{\circ} \mathrm{C}$, and therefore it was chosen as a reference composite.

Based on these results, self-healing experiments were carried out by exposing magnetic composite with $20 \mathrm{wt} \%$ particle loading to an alternating magnetic field at a frequency of $110.1 \mathrm{kHz}$ (Fig. 6). As described previously, the specimen was cut with a razor blade into two equal parts, which were subsequently rejoined. Then, the damaged sample was placed in the centre of the induction coil and an alternating magnetic field was applied. Fig. 7 compares the mechanical properties of the native composite and the damaged composite after exposure to AMF. Even though complete healing was not achieved, the composite exhibited promising self-healing efficiencies, calculated as $\eta_{\varepsilon}=78 \%$ and $\eta_{\sigma}=70 \%$ respectively. These values are higher than the ones reported for the self-healing of the pure material by direct heating at $55{ }^{\circ} \mathrm{C}$.

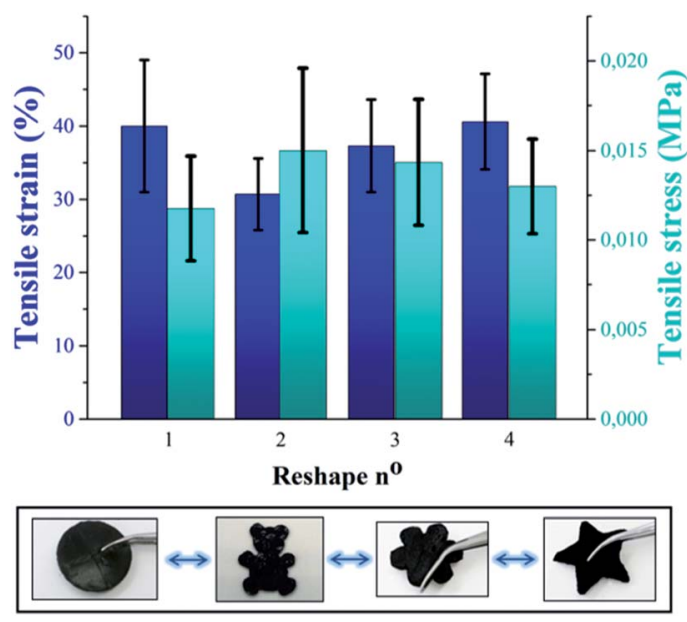

Fig. 4 Comparison of tensile stress and tensile strain of P(PDMSMAco-UPyMA) after repeated recycling by solvent casting. Multiple shapes obtained by consecutively reprocessing the material are displayed in the bottom figure (copolymer filled with iron oxide particles is used as an example).
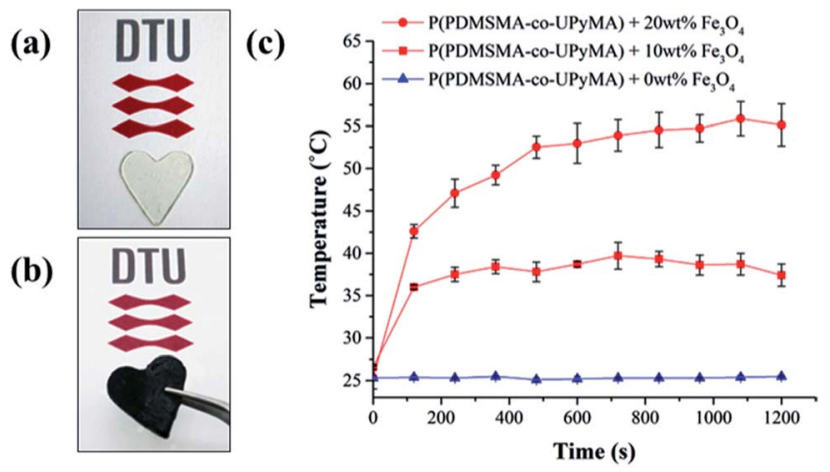

Fig. 5 (a) Pure P(PDMSMA-Co-UPyMA) and (b) P(PDMSMA-CoUPyMA) filled with iron oxide particles. (c) Heating temperature profiles of P(PDMSMA-Co-UPyMA) filled with 0, 10, and 20 wt\% particles and exposed to an alternating magnetic field at an applied frequency of $110.1 \mathrm{kHz}$

Even though the higher detected temperature upon exposure to AMF was $55{ }^{\circ} \mathrm{C}$, it should be mentioned that the bulk temperature of the composite was probably higher than the detected one. The temperature was measured by an IR-gun thermometer, which in capable of detecting only the temperature on the surface of the sample.

Moreover, scanning electron microscopy was exploited to observe the morphology of the cut interface of the composite after the self-healing experiments. In the SEM images in Fig. 8, the trace of the healed interface is discernible, and no gaps are visible. This suggests that the razor cut was filled with the material and, therefore, the polymer chains were able to diffuse through the damaged interface. ${ }^{32}$

After assessing the self-healing capability of the novel P(PDMSMA-co-UPyMA) by induction heating, the optimised procedure was subsequently exploited to investigate the selfhealing performance of a previously reported copolymer synthesised by the free radical polymerisation of 2-methoxyethyl

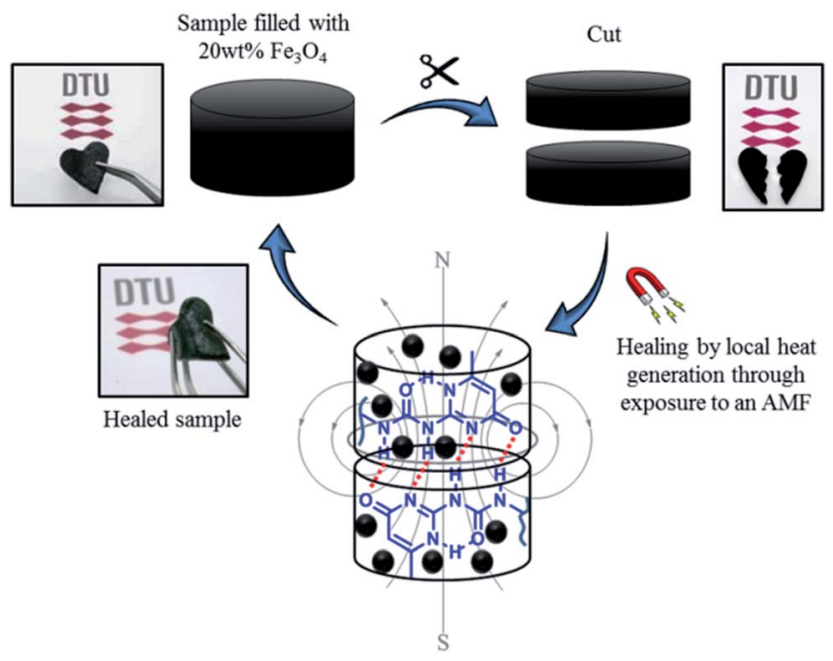

Fig. 6 Schematic illustration of the alternating magnetic field mechanism activated self-healing of the novel P(PDMSMA-co-UPyMA) filled with $20 \mathrm{wt} \%$ iron oxide particles. 


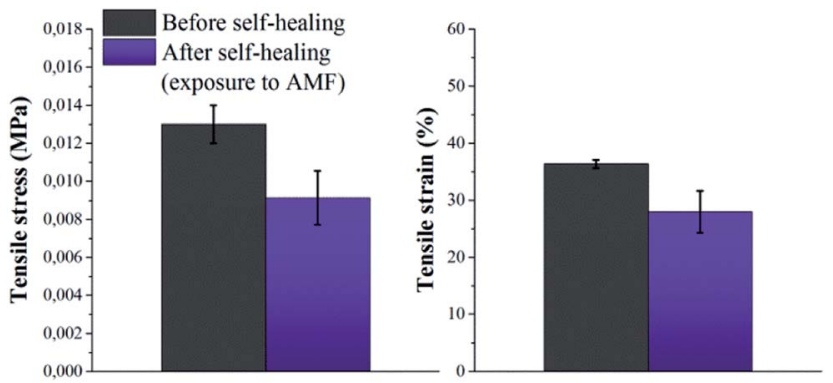

Fig. 7 Tensile stress and tensile strain of P(PDMSMA-CO-UPyMA) filled with 20 wt\% iron oxide particles, before and after healing for $2 \mathrm{~h}(5$ cycles) following exposure to an alternating magnetic field.
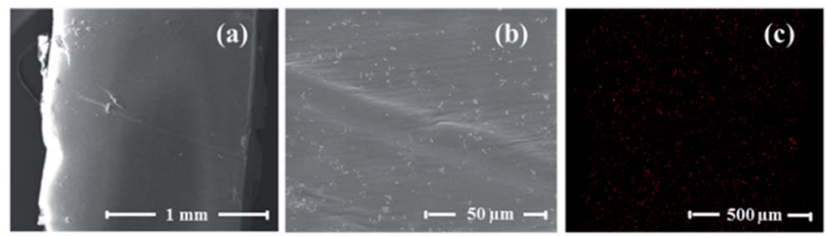

Fig. 8 (a) and (b) SEM images of the magnetic composite filled with $20 \mathrm{wt} \% \mathrm{Fe}_{3} \mathrm{O}_{4}$ after self-healing experiments following exposure to AMF and (c) elemental mapping of the specimen by EDS (iron distribution is visualised as red dots).

acrylate (MEA) and (UPyMA) monomers (Fig. S7 $\dagger$ ). ${ }^{16} \mathrm{P}(\mathrm{MEA}-\mathrm{co}$ UPyMA) and P(PDMSMA-co-UPyMA) are characterised by a similar UPy molar fractions, $6 \%$ and $11 \%$ respectively. Nevertheless, the difference in chemistry of the main repeating unit imparts significantly diverse characteristics to the materials. $\mathrm{P}(\mathrm{MEA}-c o$-UPyMA) was filled with $20 \mathrm{wt} \%$ iron oxide particles, the specimen cut with a razor blade in the middle and then exposed to an AMF with the same applied frequency of $110.1 \mathrm{kHz}$ and the same time of exposure (corresponding to five AMF cycles). Self-healing ability was evaluated by scanning electron microscopy (Fig. S8†). Similarly to P(PDMSMA-coUPyMA), no gap was detectable in the cut interface, indicating that induction heating developed through exposure to AMF successfully promotes the rearrangement of hydrogen-bonding UPy groups. Even though self-healing efficiency should be quantified further, the results suggest that the self-healing method is versatile and may be effective in different systems.

\section{Conclusions}

Two thermoplastic elastomers were developed based on supramolecular 2-ureido-4[1H]-pyrimidone (UPy) selfassembling motifs. Both elastomers possessed excellent selfhealing properties and thermoplastic nature while maintaining their elasticity at room temperature $\left(G^{\prime}\right.$ approximately 10 fold larger than $G^{\prime \prime}$ ). Furthermore both elastomers possessed fast self-healing times and were fully self-healed after 1 hour at $70{ }^{\circ} \mathrm{C}$. The PDMSMA-co-UPyMA silicone elastomer proved to be remouldable multiple times with no detoriation of the properties and thus proving a robust and stable elastomer matrix for a thermoplastic silicone elastomer. Finally the silicone elastomer were loaded with magnetic particles to allow for selfhealing by remote stimulus, namely by use of an alternating magnetic field. Efficient self-healing was also achieved by exposure to the alternating magnet, and the fillers were proven not to alter the elastomer properties to any significant extent.

\section{Conflicts of interest}

There are no conflicts to declare.

\section{Acknowledgements}

L. Yu and A. L. Skov acknowledge funding from The Danish Research Council. Also valuable discussions with Professor Søren Hvilsted are acknowledged.

\section{Notes and references}

1 M. D. Hager, P. Greil, C. Leyens, S. van der Zwaag and U. S. Schubert, Adv. Mater., 2010, 22, 5424-5430.

2 S. R. White, N. R. Sottos, P. H. Geubelle, J. S. Moore, M. R. Kessler, S. R. Sriram, E. N. Brown and S. Viswanathan, Nature, 2001, 409, 794-797.

3 C. J. Hansen, W. Wu, K. S. Toohey, N. R. Sottos, S. R. White and J. A. Lewis, Adv. Mater., 2009, 21, 4143-4147.

4 K. S. Toohey, N. R. Sottos, J. A. Lewis, J. S. Moore and S. R. White, Nat. Mater., 2007, 6, 581-585.

5 N. Kuhl, S. Bode, R. K. Bose, J. Vitz, A. Seifert, S. Hoeppener, S. J. Garcia, S. Spange, S. van der Zwaag, M. D. Hager and U. S. Schubert, Adv. Funct. Mater., 2015, 25, 3295-3301.

6 D. Habault, H. Zhang and Y. Zhao, Chem. Soc. Rev., 2013, 42, 7244-7256.

7 T. Chuo, T. Wei and Y. Liu, Polym. Chem., 2013, 51, 33953403.

8 X. Yang, H. Yu, L. Wang, R. Tong, M. Akram, Y. Chena and X. Zhaia, Soft Matter, 2015, 11, 1242-1252.

9 G. Akaya, A. Hassan-Raeisib, D. C. Tuncaboyluc, N. Orakdogena, S. Abdurrahmanoglud, W. Oppermann and O. Okay, Soft Matter, 2013, 9, 2254-2261.

10 S. Burattini, H. M. Colquhoun, J. D. Fox, D. Friedmann, B. W. Greenland, P. J. F. Harris, W. Hayes, M. E. Mackay and S. J. Rowan, Chem. Commun., 2009, 6717-6719.

11 C. Li, C. Wang, C. Keplinger, J. Zuo, L. Jin, Y. Sun, P. Zheng, Y. Cao, F. Lissel, C. Linder, X. You and Z. Bao, Nat. Chem., 2016, 8, 618-624.

12 F. B. Madsen, L. Yu and A. L. Skov, ACS Macro Lett., 2016, 5, 1196-1200.

13 F. H. Beijer, R. P. Sijbesma, H. Kooijman, A. L. Spek and E. W. Meijer, J. Am. Chem. Soc., 1998, 120, 6761-6769.

14 R. P. Sijbesma, F. H. Beijer, L. Brunsveld, B. J. B. Folmer, J. H. K. Ky Hirschberg, R. F. M. Lange, J. K. L. Lowe and E. W. Meijer, Science, 1997, 278, 1601-1604.

15 K. Yamauchi, J. R. Lizotte and T. E. Long, Macromolecules, 2003, 36, 1083-1088. 
16 A. Shabbir, I. Javakhishvili, S. Cerveny, S. Hvilsted, A. L. Skov, O. Hassager and N. J. Alvarez, Macromolecules, 2016, 49, 3899-3910.

17 F. B. Madsen, A. E. Daugaard, S. Hvilsted and A. L. Skov, Macromol. Rapid Commun., 2016, 37, 378-413.

18 D. L. Bernik, Recent Pat. Nanotechnol., 2007, 3, 186-192.

19 F. Ilievski, A. D. Mazzeo, R. F. Shepherd, X. Chen and G. M. Whitesides, Angew. Chem., 2011, 50, 1890-1895.

20 J. C. Mcdonald and G. M. Whitesides, Acc. Chem. Res., 2002, 35, 491-499.

21 C. Lei, S. Li, R. Xu and Y. Xu, J. Elastomers Plast., 2012, 44, 563-574.

22 A. S. Fawcett and M. A. Brook, Macromolecules, 2014, 47, 1656-1663.

23 L. Yang, Y. Lin, L. Wang and A. Zhang, Polym. Chem., 2014, 5, 153-157.

24 S. Tazawa, A. Shimojima, T. Maeda and A. Hotta, J. Appl. Polym. Sci., 2017, 134, 45419.
25 C. C. Corten and M. W. Urban, Adv. Mater., 2009, 21, 50115015.

26 A. Shaaban and A. M. Schmidt, Smart Mater. Struct., 2016, 25, 084018.

27 A. S. Ahmes and R. V. Ramanujan, J. Mater. Res., 2015, 30, 946-958.

28 T. Yan, K. Schroter, F. Herbst, W. H. Binder and T. ThurnAlbrecht, Sci. Rep., 2016, 6, 32356.

29 Y. H. Kim and R. P. Wool, Macromolecules, 1983, 16, 11151120.

$30 \mathrm{~W}$. Suwanwatana, S. Yarlagadda and J. W. Gillespie Jr, Compos. Sci. Technol., 2006, 66, 2825-2836.

31 N. Hohlbein, A. Shaaban and A. M. Schmidt, Polymer, 2015, 69, 301-309.

32 K. A. Williams, A. J. Boydston and C. W. Bielawski, J. R. Soc., Interface, 2007, 4, 359-362. 